\title{
RECONSTRUINDO FORMAS DE SOCIABILIDADE ATRAVÉS DA COOPERAÇÃO
}

\section{RECONSTRUCTING FORMS OF SOCIABILITY THROUGH COOPERATION}

André Luiz Papaléo

\section{Palavras-chave}

Cooperativismo; Cultura solidária; Autogestão.

\section{Key-Words}

Cooperativism; Solidary culture; Self management.

Esta obra, resultado de Tese de Livre-docência, apresenta três anos de pesquisa em que o autor acompanhou duas cooperativas populares tanto em suas reuniões formais quanto informais.

As cooperativas pesquisadas foram a Interativa e a Coopera. Ambas fundadas no ano de 1999 e constituídas por um número aproximado de 25 integrantes. A primeira atua nas áreas de manutenção predial, serviços de jardinagem e de limpeza, sendo formada por pessoas das classes populares, predominantemente mulheres. A segunda, constituída por universitários recém-formados na Universidade de São Paulo (USP) nas áreas de Engenharia, Arquitetura, Sociologia e Administração, desenvolve projetos, construções e transformações de edificações comerciais e industriais em residenciais e fornece também assessoria a movimentos sociais.

Com base no trajeto teórico da Cultura Solidária, o objetivo almejado foi o de estabelecer a associação entre conceitos e práticas, sem a qual se tornaria difícil a tarefa de compreender o elevado grau de maturidade de tais projetos devido aos conflitos e às barreiras presentes em suas práticas cotidianas.

O livro nos conduz, portanto, por três capítulos envolventes elaborados através de inter-relações constantes entre apontamentos teóricos sobre aspectos do social, como desemprego estrutural e 
influências da racionalidade administrativa na construção de formas de sociabilidade, e a voz significativa dos entrevistados.

Com a finalidade de evitar o caráter de passividade do termo "cooperado", em geral utilizado como referência aos trabalhadores de cooperativas, o autor opta pela variante "cooperante" que, segundo ele, melhor se adéqua às prerrogativas democráticas e cooperativas deste tipo de organização produtiva.

O lúdico representa um dos pontos analisados pela sua importância no processo de construção e reconstrução das relações estabelecidas entre os cooperantes. Há uma relação dialética entre lazer e cotidianidade $^{1}$, de modo que, manifestações lúdicas trazem a possibilidade de crítica e ruptura com a vida cotidiana.

O Brasil possui uma grande quantidade de cooperativas. Destas, muitas não seguem os princípios de igualdade e democracia, pelo contrário, se beneficiam suprimindo direitos trabalhistas. São conhecidas como "coopergatos" ou "cooperfraudes". No sentido oposto, as cooperativas populares buscam efetivamente o caminho da autogestão e da recusa de formas de discriminação social.

Conciliar produção com formas de interação social que privilegiem a solidariedade em detrimento do egocentrismo não constitui tarefa fácil, ainda mais num contexto social com poucos espaços de vivência democrática, em que predomina a passividade no que diz respeito à participação social. "Uma gastronomia dos olhos". Vemos tudo, mas não nos envolvemos com nada.

Contudo, existem formas de resistência à situação degradante em que se apresenta a sociedade contemporânea. Para o autor, os sentimentos e manifestações de solidariedade ainda são muitos. Eles não se perderam no tempo, pois possuem raízes profundas na alma popular. Nós é que fomos perdendo muito da capacidade de dicerni-los.

${ }^{1}$ Henry LEFEBVRE. Critique de la vie quotidienne. Paris: L'Arque, 1958.

Conexões: revista da Faculdade de Educação Física da UNICAMP, Campinas, v. 7, n. 2, p. 13-23, maio/ago. 2009. 126 ISSN: 1983-930. 
Assim, através de empenho por renovação, o autor aposta que é viável a ascensão de uma cultura solidária capaz de superar a indiferença e a insensibilidade diante das diversas formas de violência às quais milhões de pessoas são submetidas.

A zona rural apresenta até hoje muitos exemplos de generosidade e ajuda recíproca, fruto de constantes reinterpretações da tradição popular fortemente associada à religiosidade católica. A coesão social ocorre, por exemplo, através de festas religiosas ou formas de trabalho coletivo mutirões - entre outras.

No meio urbano, as cooperativas estudadas também trazem significativos exemplos de coesão. Ao falar da Interativa, o autor discute o quão importante é a opção da busca pela cidadania assumida pelos cooperantes e demonstrada através da participação efetiva nas decisões que lhes dizem respeito. Tal importância é ainda ampliada quando considerada a dura e, não raro, ameaçadora condição de vida destas pessoas.

Questionado sobre o significado da cooperativa, um dos entrevistados diz: "Ela não é só o emprego, não é só o trabalho, não é só gerar renda. Para mim, [...] as cooperativas são as pessoas que fazem parte delas" (OLIVEIRA, 2006, p.23).

Questões conflitantes e recorrentes no universo cooperativista e da Economia Solidária não deixam de marcar território também nesta organização. A hierarquia abusiva foi percebida pelo pesquisador durante uma saída dos cooperantes a campo para realizarem determinado serviço. Segundo o autor, problemas deste tipo não podem ficar camuflados, pois aponta contradições à prática solidária ali proposta e geram constrangimentos, mágoas, silêncios dolorosos. No entanto, muitos cooperandos ainda não se deram conta da força que possuem as palavras; outros, o que parece ser ainda pior, calam-se diante de algo que discordam. Tais atitudes parecem comuns por parte dos que, não sabendo ler, sentem-se constrangidos e com dificuldade de articular suas idéias.

$\mathrm{O}$ assunto sobre o valor das retiradas (equivalente ao salário) também foi abordado por um integrante. Para ele, sua retirada deveria ser maior, e não igual a dos demais, visto que determinados trabalhos apenas podiam ser aceitos devido à sua especialização para tal. Neste momento, o pesquisador, com 
perspicácia, não se posicionou a favor ou contra esta colocação, apenas informou não se tratar de certo ou errado e sim uma questão que deve ser resolvida por cada cooperativa.

Outros momentos e conversas na cooperativa apontaram a multiplicidade de formas de expressão da cultura solidária. Dentre elas, o autor destaca a possibilidade sempre presente de empréstimo aos mais necessitados, como quando uma cooperante teve de se ausentar para dar à luz, ou quando outro cooperante se acidentou e teve que se afastar sem direito à remuneração, pois não tinha um ano de contribuição no INSS, no que se aprovou a compra de uma cesta básica para ajudá-lo.

A Educação é também muito valorizada. Há situações em que se utiliza dinheiro da cooperativa para pagar cursos. Como não há possibilidade de todos fazerem, é realizado sorteio.

Um dos motivos de se atribuir importância à Educação, nas palavras de uma cooperanda, é que "a cooperativa precisa ter seus próprios formadores, para ir educando os novos que entram" (OLIVEIRA, 2006, p.72), enquanto outro motivo destacado é que há interesse que os membros aumentem o grau de escolaridade. Felizmente, conforme destaca o autor, existe, além da vontade individual, um grande incentivo coletivo. Uma terceira característica está na chance dada aquele(a) que por problemas como, por exemplo, alcoolismo, atrapalharam de alguma forma a cooperativa. Compreensão raramente encontrada em empresas comuns.

A participação de crianças nas reuniões também demonstra, segundo o autor, um dado de cultura solidária. Uma possível mescla entre obediência e lição solidária faz com que as crianças estejam presentes se divertindo, mas sem atrapalhar; aprendendo, mas também ensinando com seus comportamentos.

O cotidiano na cooperativa transforma membros em indivíduos mais confiantes e participativos. Este e outros passos são pouco a pouco conquistados, como a adesão mais intensa à cooperativa. Conforme relato de um dos cooperantes: "A cooperativa trabalha ajudando um ao outro. [...] No meio das pessoas que entende, a pessoa vai entendendo também” (OLIVEIRA, 2006, p.59).

Segundo Oliveira, o espírito que governa a outra cooperativa pesquisada, a Coopera, é o de comunidade. Um problema é sempre encarado como de todos. Da mesma forma, os conflitos Conexões: revista da Faculdade de Educação Física da UNICAMP, Campinas, v. 7, n. 2, p. 13-23, maio/ago. 2009. ISSN: 1983-930. 
existentes não deixam margem a rancores entre os membros. É bastante provável que parte considerável destas atitudes coletivas tenha se originado a partir da participação dos cooperantes no movimento estudantil - que os mesmos têm orgulho de pontuar - durante o período de formação na USP.

Após descrever duas visitas com os integrantes da Coopera - um ex-banco que se tornou moradia no Brás e um antigo escritório da ferrovia - o autor presencia novamente o desembaraço e a educação de crianças. Presente no ambiente da segunda visita as crianças, sem dúvida, contribuíam muito para tornar tal ambiente menos desolador.

Retornando à discussão sobre o lúdico, este pode ser percebido nas reuniões de ambas cooperativas o que ajuda a transformar o clima, tornando-o mais caloroso e alegre sem que se perca de vista as responsabilidades implícitas. Para o autor, isto demonstra mais uma potencialidade do trabalho autogestionário.

Uma questão feita pelo autor é se é possível afirmar que o ingresso numa cooperativa pode modificar as pessoas a ponto destas construírem solidariedade, ainda mais num momento em que poucas se sensibilizam com isto. $\mathrm{O}$ fato é que não basta apenas a convicção cooperativista, é preciso exercer esta prática no cotidiano, ao passo que não se pode esquecer do aspecto da reeducação enquanto processo em que um indivíduo adquire um sistema de valores ao desenvolver-se na cultura em que se encontra, e neste sentido o grupo social é facilitador.

Assumir o cooperativismo é diferente de ter simpatia por ele. Muitas vezes o indivíduo não está preparado para assumir determinada situação, pois, ainda encontra-se desarmado emocionalmente diante dos preconceitos. No entanto, alguns cooperandos sem perceber já praticam cultura solidária, mas é importante que este novo sistema de valores o envolva por completo para evitar que o indivíduo se sinta na marginalidade entre dois sistemas diferentes, o que quer abandonar e o que não acatou completamente.

De fato, a aquisição de um novo sistema de valores é facilitada pelo sentimento de que todos estão no mesmo barco. Isso fortalece os laços e o enfrentamento das dificuldades, embora se trate de um processo incerto e contraditório que jamais se dá de forma linear e exige paciência e persistência.

Conexões: revista da Faculdade de Educação Física da UNICAMP, Campinas, v. 7, n. 2, p. 13-23, maio/ago. 2009. 129 ISSN: 1983-930. 
Uma atmosfera de liberdade é essencial para este processo se concretizar, pois, conforme o autor (OLIVEIRA, 2006, p.112), "percepção social e liberdade de escolha estão estreitamente correlacionadas". Porém, é consenso entre os entrevistados que a liberdade não pode ser irrestrita justamente pelo respeito ético entre os indivíduos.

Para Durkheim ${ }^{2}$, a coerção que o grupo exerce sobre o individual é um meio de fazer com que este ultrapasse a si mesmo. Pessoas com interesses comuns não se associam apenas para defendê-los, mas para se fortalecerem diante dos adversários e para levarem juntos a mesma vida moral.

Neste sentido, não há contradição entre autonomia individual e senso de dependência à sociedade. As interações sociais favorecem a explicitação de nosso inacabamento.

Para que haja cooperação não é possível haver formação de pequenos grupos dentro de determinado ambiente, diz uma cooperanda da Interativa. Isso é reforçado por um cooperando da Coopera quando diz: "ficar com joguinho político é o aspecto mais negativo que pode haver em uma cooperativa" (OLIVEIRA, 2006, p.116).

Sobre outra tendência de solidariedade em Durkheim (1977), o autor fala da simpatia que ele nutriu pelo socialismo no final de sua vida ao perceber que a solidariedade da divisão social do trabalho sob o capitalismo era pouco viável.

Numa sociedade em que ajudar uns aos outros parece ocorrer apenas se houver interesses, uma "sociabilidade contabilizada", gestos de solidariedade parecem ser praticas de outro mundo, mas não o são.

Quando o assunto sobre assistencialismo é discutido, Mariza da Interativa é radical em dizer que, às vezes, é necessário sim ajudar ao outro que está sentindo fome, dor. Ela lembra indignada de uma vez que pediu para uma estudante da USP comprar-lhe um lanche, pois estava sem dinheiro, e recebeu um "não" como resposta. A estudante disse que não iria fazer assistencialismo, mas a cooperante se

${ }^{2}$ Émile DURKHEIM. A divisão do trabalho social. Lisboa: Presença, 1977. Citado pelo autor na p.113.

Conexões: revista da Faculdade de Educação Física da UNICAMP, Campinas, v. 7, n. 2, p. 13-23, maio/ago. 2009. 130 ISSN: 1983-930. 
lembra bem da vez em que deu dinheiro para que estudantes pudessem pegar o ônibus para ir embora da Universidade.

A cooperação é um exercício que procura ir além da ajuda, pois segundo o autor, implica partilha dos benefícios. "Quem atua cooperativamente acredita que o que faz é bom para os outros é também para si” (OLIVEIRA, 2006, p.122).

Paralelamente, integrantes das cooperativas confirmaram haver também competição ao lado da cooperação. No entanto, isto não se dá como na heterogestão em que, em geral, há incompatibilidade entre as duas ocorrências, de modo a prevalecer a competição.

Quanto ao rodízio de funções, um dos possíveis indicadores de autogestão, alguns defendem que deve ser avaliado com cuidado. Os princípios não devem ser vistos como dogmas inquestionáveis e sim como apontamento de possibilidades. Não é apenas a mudança das pessoas nos cargos um garantidor de autogestão, conforme informa a cooperanda Cecília.

Ainda com Cecília, "as pessoas têm envolvimentos diferenciados e querem que as coisas sejam assim. A diferenciação garante às pessoas que elas possam circular aqui dentro com maior ou menor envolvimento" (OLIVEIRA, 2006, p.131).

Assim, estamos de acordo com o autor no sentido de que não é possível e nem válido resumir o cooperativismo à aplicação de esquemas. Deve haver sim flexibilidade diante dos problemas complexos do dia-a-dia, o que não significa que os pontos essenciais são desconsiderados.

Ficou demonstrado que ambas cooperativas produzem e vivem o cooperativismo e a economia solidária. Consensos são sempre buscados antes de se colocar uma proposta conflitante em votação. Os indivíduos antes desempregados voltam a se enxergar com cidadãos, como pessoas úteis.

A dificuldade de não sucumbir frente às dificuldades encontradas é enorme nas cooperativas, ainda mais por tratar-se de ambientes cujas proximidades apresentam muita violência, mas conforme aponta o autor, os envolvidos acabam sendo radicais em sua escolha mesmo que imperceptivelmente, pois Conexões: revista da Faculdade de Educação Física da UNICAMP, Campinas, v. 7, n. 2, p. 13-23, maio/ago. 2009. ISSN: 1983-930. 
“agregam convicções e práticas; querem e praticam, para si e para o outro, uma sociabilidade solidária, que é dissonante de práticas e saberes consagrados” (OLIVEIRA, 2006, p.144).

Finalizando, Coopera e Interativa são legítimas cooperativas populares inscritas na economia solidária. Nelas, pessoas se descobrem ou se redescobrem como cidadãos. Se o dia-a-dia não eliminou por completo práticas e pensamentos típicos das empresas capitalistas, pouco a pouco esta visão vai mudando.

A cultura e economia solidárias, nas palavras do pesquisador, "inauguram um projeto original, uma possibilidade radical de humanização. [...] capaz de acolher democraticamente a pluralidade de todos nós” (OLIVEIRA, 2006, p.148-149). E tanto Coopera quanto Interativa abraçam este desafio.

\section{Referência da obra resenhada}

OLIVEIRA, P. de S. Cultura solidária em cooperativas: projetos coletivos de mudança de vida. São Paulo: EDUSP, 2006.

\section{André Luiz Papaléo}

Faculdade de Educação Física - UNICAMP

Recebido: 30/06/2009

Aceito em: julho 2009 